\title{
Evolution of surface hardness of concrete under sulfate attack
}

\author{
Wei-yi Ouyang ${ }^{\mathrm{a}}$, Jian-kang Chen ${ }^{\mathrm{a}, \mathrm{b}, *}$, Min-qiang Jiang $^{\mathrm{c}}$ \\ ${ }^{a}$ The Faculty of Mechanical Engineering and Mechanics, Ningbo University, Ningbo, China \\ ${ }^{\mathrm{b}}$ State Key Laboratory of Turbulence and Complex Systems, Peking University, Beijing, China \\ ' State Key Laboratory of Nonlinear Mechanics (LNM), Institute of Mechanics, Chinese Academy of Sciences, Beijing, China
}

\section{H I G H L I G H T S}

- It investigates the evolution of surface hardness of concrete under sulfate attack.

- It reveals reinforcing effect and weakening effect in concrete during erosion.

- Reinforcing and weakening effect are all induced by delayed ettringite and gypsum.

- It uses an integral method to analyze the attenuation tendency of surface hardness.

\section{A R T I C L E I N F O}

\section{Article history:}

Received 3 October 2013

Received in revised form 22 November 2013

Accepted 27 November 2013

Available online 29 December 2013

\section{Keywords:}

Surface hardness

Sulfate attack

Concrete

Damage evolution

\begin{abstract}
A B S T R A C T
Under sulfate attack, the erosion damage is not uniformly distributed in concrete, but firstly takes place at the surface since the sulfate radical ions diffuse from surface to inner of the material. In order to investigate the damage degree, the variation of surface hardness of concrete was investigated in this study. The corrosion experiments continued about 330 days, and the evolution of surface hardness of concrete samples was detected by rebound method. Meanwhile, SEM observation and XRD test for concrete samples were also carried out. It was found that exist a competition mechanism of enhancement effect and weakening effect, because the surface hardness of concrete monotone increases at the initial stage. SEM observation and XRD test indicated that both enhancement and weakening effect are all caused by delayed ettringite and gypsum. The enhancement mechanism is produced by the filling effect of delayed ettringite and gypsum, and the weakening mechanism is induced by damage evolution due to their expansion force. Based on the experimental results, a new method was suggested to express the damage degree. The analysis results indicated that the water-to-cement ratio of concrete and the concentration of sulfate solution strongly affect the attenuation of the surface hardness.
\end{abstract}

(c) 2013 Elsevier Ltd. All rights reserved.

\section{Introduction}

Durability of concrete structures under sulfate attack in marine environment is an important topic, and it attracts some attentions in research. It has been recognized that when sulfate ions diffuse in concrete, the chemical reaction may take place, namely, sulfate ions may be combined by the hydration solution in pores of concrete to form gypsum and delayed ettringite. In this paper, such ettringite formed by diffused sulfate ions is called delayed ettringite. Under the expansion force of the ettringite and gypsum, micro-damage evolution may occur and lead to the deterioration of concrete material [1,2]. Efforts have been made to the analysis on the attenuation of durability caused by sulfate attack. For instance,

\footnotetext{
* Corresponding author at: The Faculty of Mechanical Engineering and Mechanics, Ningbo University, Ningbo, China. Tel.: +86 57487600075; fax: +86 57487608358 .

E-mail addresses: chenjiankang@nbu.edu.cn, chenjiankang1957@163.com (J.-k. Chen).
}

Yimaz et al. studied the effect of sulfate ion and $\mathrm{pH}$ value on concrete [3]. Marchand et al. analyzed the influence of sulfate on durability of concrete [4]. Planel et al. obtained experimental results on micro-crack nucleation in cement mortar due to sulfate attack [5]. Rozière et al. studied the mass evolution and expansion property of concrete under sulfate attack and calcium separating out [6]. Pipilikaki et al. studied the expansion of concrete immersed in calcium sulfate solution of $5 \%$ concentration at $50{ }^{\circ} \mathrm{C}$ [7]. Plowman and Cabrera [8], and Chindaprasirt [9] studied the sulfate resistance of concrete added with fly ash and other components. Lee et al. investigated the strength loss behavior of concrete filled with silica [10]. Gospodinov et al. studied the effect of diffusion of sulfate ions on the micro-structure of cement stone [11]. Mironova et al. investigated the effect of liquid push out of the material capillaries under sulfate ion diffusion in cement composites [12]. Chen et al. studied damage evolution in cement mortar immersed in sodium sulfate solution for 425 days using ultrasonic techniques [13], and measured the growth properties of delayed ettringite and 
gypsum by virtue of XRD method [14]; Zhang et al. tested the static and dynamic modulus of ettringite [15], and investigated the evolution of flexural strength of concrete due to sulfate attack [16]; Zhu et al. studied the expansion strain of concrete immersed in sodium sulfate solution, and developed an increment model for expansion strain based on damage evolution [17].

Note that the erosion damage starts at the surface because the nature of the diffusion of sulfate radical ions is from surface to inner of concrete. In other words, the erosion damage is not uniformly distributed in a concrete. Hence, variation of surface hardness could accurately reflect the degree of erosion. In the present study, the rebound method was adopted to examine the evolution of surface hardness. SEM observation and XRD detect were also carried out for finding the mechanism of such an evolution.

Generally, rebound surface hardness was used to approximately predict the compressive strength or empirical constitutive relation of concrete [18-20]. In this study, however, close attention was only paid to the variation of rebound index due to sulfate attack and related mechanism without considering the relation between the surface hardness and compressive strength.

Firstly, the cement mortar samples were formed and then put into sodium sulfate solutions of different concentrations. Secondly, the rebound testing was carried out at different erosion times. In order to more accurately detect the variation of surface hardness of samples due to sulfate attack, the rebound testing was carried out at the random 16 points on the surface, and taking average value as rebound index by ignoring 3 maximum values and 3 minimum values. Thirdly, the micro-observation of ettringite growth at the surface of samples was performed by means of SEM method. It was found that the variation of surface hardness is dominantly caused by the filling effect and damage evolution due to the action of delayed ettringite and gypsum. Finally, the mechanism of variation of surface hardness is analyzed, and a new method was suggested to describe the attenuation of the surface hardness of concretes under sulfate attack.

\section{Test on the variation of surface hardness of cement mortar}

In this study, samples of cement mortar have been produced using ordinary Portland cement (CEM I-32.5). Mix design of samples is presented in Table 1.

Two types of samples were prepared, one was for measuring the surface stiffness, which are denoted as $\mathrm{Hi}(i=1-4)$ with a size of $150 \times 150 \times 150 \mathrm{~mm}$ (shown in Fig. 1 ), the other was for observing growth of ettringite, which are denoted as $\mathrm{Zi}(i=1-3)$ with size of $10 \times 10 \times 60 \mathrm{~mm}$ (shown in Fig. 2).

Samples Hi $(i=1-4)$ were immersed in sodium sulfate solution of $3 \%$ and $8 \%$ concentration for 330 days. Under sulfate attack, the change of mechanical properties of concrete may occur, such as compressive strength, modulus, Poisson's ratio, and surface hardness. In this study, the rebound method was adopted to measure the variation of the surface hardness (presented by rebound index) of samples during the erosion time.

Owing to sulfate attack, the surface hardness, $R$, should be a function of erosion time $t$, namely,

$R=R(t)$

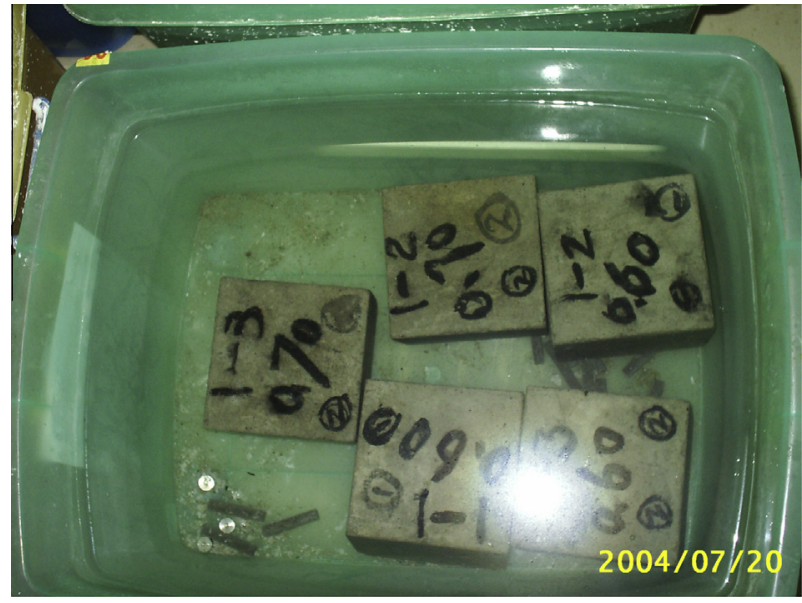

Fig. 1. Samples immersed in sodium sulfate solution for rebound test.

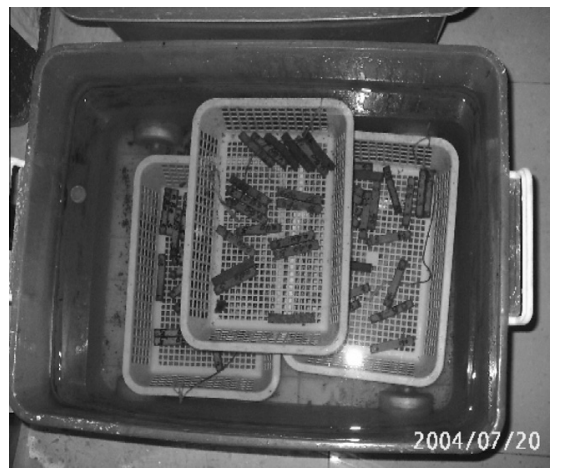

Fig. 2. Samples immersed in sodium sulfate solution for SEM and XRD tests.

The relative variation of surface hardness is defined as

$R_{r}(t)=\left(R-R_{0}\right) / R_{0} \times 100 \%$

where $R_{0}$ is the initial surface hardness.

The testing procedure of test on the variation of the surface hardness is as follows:

(1) Taking the samples out of solution, and dying for $1 \mathrm{~h}$.

(2) Randomly selecting 16 different points on one surface, and testing the surface hardness by means of ZC5 rebound instrument of mortar (shown in Fig. 3).

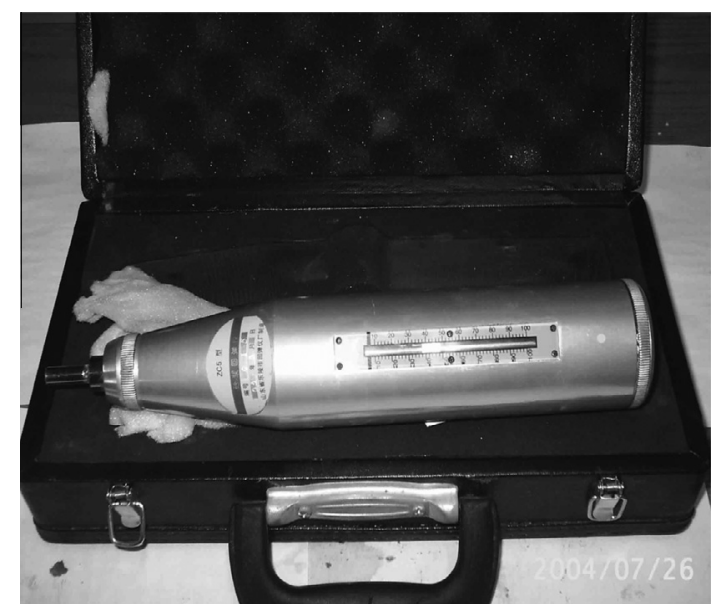

Fig. 3. ZC5 rebound instrument.

Table 1

Mix design of concrete.

\begin{tabular}{ll}
\hline Number & Cement:sand:water \\
\hline $\mathrm{H}_{1}, \mathrm{Z}_{1}$ & $1.0: 3.0: 0.4$ \\
$\mathrm{H}_{2}, \mathrm{Z}_{2}$ & $1.0: 3.0: 0.6$ \\
$\mathrm{H}_{3}$ & $1.0: 3.0: 0.7$ \\
$\mathrm{H}_{4}, \mathrm{Z}_{3}$ & $1.0: 3.0: 0.8$ \\
\hline
\end{tabular}


(3) Calculating the average value of the test results by ignoring 3 maximum values and 3 minimum values, and taking such an average value as rebound index.

(4) Repeating such a process twelve times during erosion time of 330 days.

The experimentally obtained results were plotted in Fig. 4, in which the symbol " $w / c$ " stands for water-to-cement ratio.

It was found from Fig. 4 that there exists a critical time, $t_{c r}$. When $t<t_{c r}$, the surface hardness increases with erosion time (except for the sample with $w / c=0.4$ immersed in sulfate solution with concentration of $8 \%$ ). When $t>t_{c r}$, however, the surface hardness does not increase any further, and in some cases even tends to decrease. Table 2 lists the values of $t_{c r}$.

Fig. 4 also shows that the variation of the surface hardness significantly depends on the magnitude of water-to-cement ratio $(w /$ c) and the concentration of sulfate solution. For $w / c=0.4,0.7$, and 0.8 , surface hardness of samples immersed in sulfate solution of $3 \%$ concentration was found to be remarkably greater than that in sulfate solution of $8 \%$ concentration. However, for $w / c=0.6$, such a difference is not so significant. The mechanism of this phenomenon would be explained in the next section.

\section{Mechanism of the variation of surface hardness}

It was generally believed that the change of mechanical properties of concrete under sulfate attack is caused by the enhancement effect of delayed ettringite crystal and weakening effect of damage evolution $[3,4,10]$. When sulfate radical ions diffuse in concrete, the chemical reaction between sulfate radical ions and pore solution may occur according to the following steps,

$$
\begin{aligned}
& \mathrm{Na}_{2} \mathrm{SO}_{4}+\mathrm{Ca}(\mathrm{OH})_{2}==\mathrm{CaSO}_{4}+2 \mathrm{Na}(\mathrm{OH}) \\
& 3 \mathrm{CaSO}_{4}+4 \mathrm{CaOAl}_{2} \mathrm{O}_{3} 12 \mathrm{H}_{2} \mathrm{O}+20 \mathrm{H}_{2} \mathrm{O} \\
& \quad==3 \mathrm{CaOAl}_{2} \mathrm{O}_{3} 3 \mathrm{CaSO}_{4} 31 \mathrm{H}_{2} \mathrm{O}+\mathrm{Ca}(\mathrm{OH})_{2}
\end{aligned}
$$

\begin{tabular}{|c|c|c|c|c|}
\hline \multirow[t]{2}{*}{$\mathrm{Na}_{2} \mathrm{SO}_{4}(\%)$} & \multicolumn{4}{|c|}{$w / c$} \\
\hline & 0.4 & 0.6 & 0.7 & 0.8 \\
\hline 3 & 60 & 60 & 60 & 60 \\
\hline 8 & 14 & 28 & 60 & 90 \\
\hline
\end{tabular}

Table 2

Critical time $t_{c r}(\mathrm{~d})$.

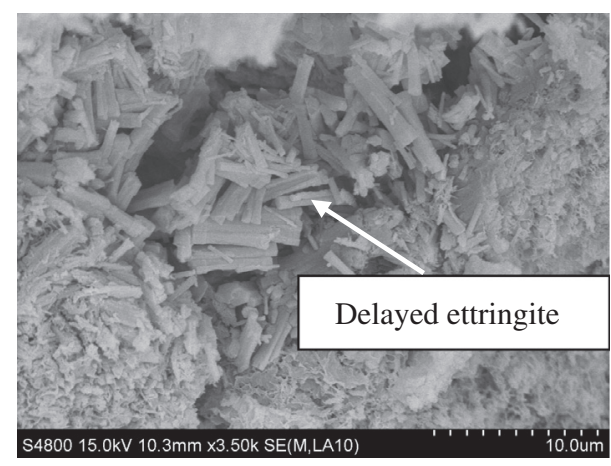

Fig. 5. SEM photo of delayed ettringite crystal.

The first term on the right hand side of Eq. (4) is delayed ettringite.

For validating such a deduction, micro-structure features of samples Zi $(i=1-3)$ were examined using X-ray diffraction (XRD) and scanning electron microscope (SEM).

Results of SEM observation and EDS spectrum of delayed ettringite crystal were shown in Figs. 5 and 6, respectively. The size and shape of delayed ettringite due to sulfate attack can be observed from Fig. 5, and the chemical components of the delayed ettringite were given by EDS spectrum in Fig. 6. It can be seen from Fig. 4 that the delayed ettringite may fill pores of samples.
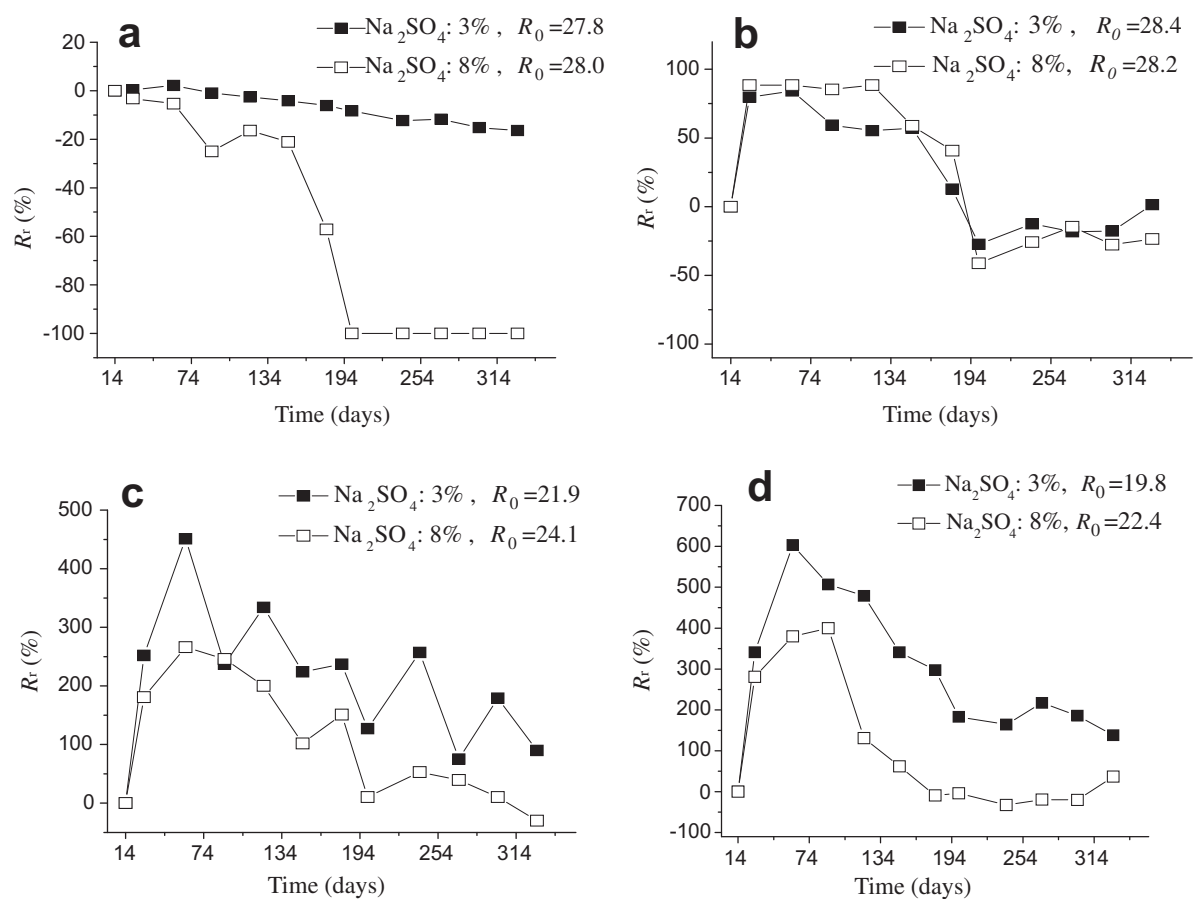

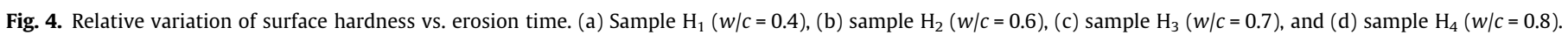




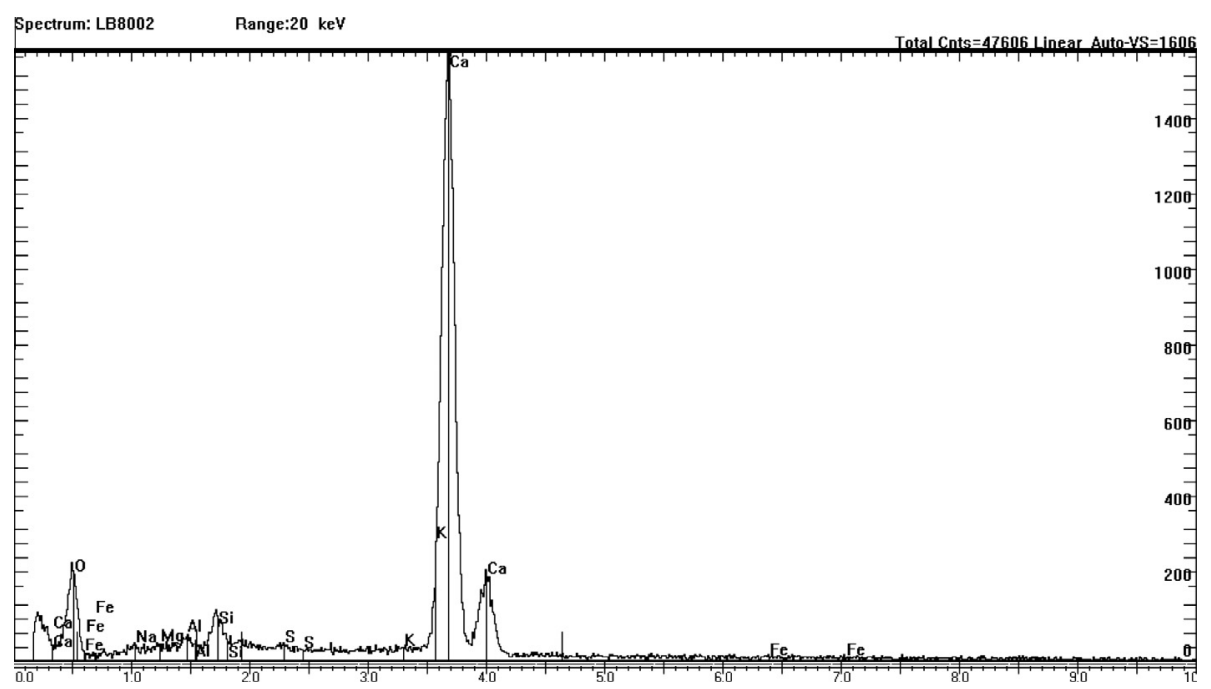

Fig. 6. EDS spectrum of delayed ettringite crystal.
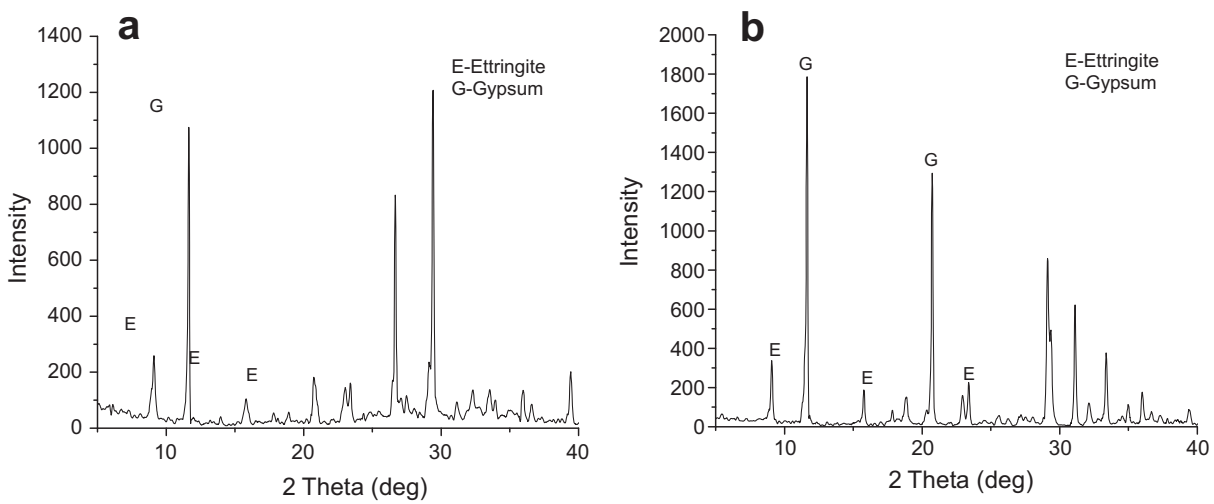

Fig. 7. XRD analysis of samples $(w / c=0.4)$. (a) Erosion time: 210 days and (b) erosion time: 250 days.
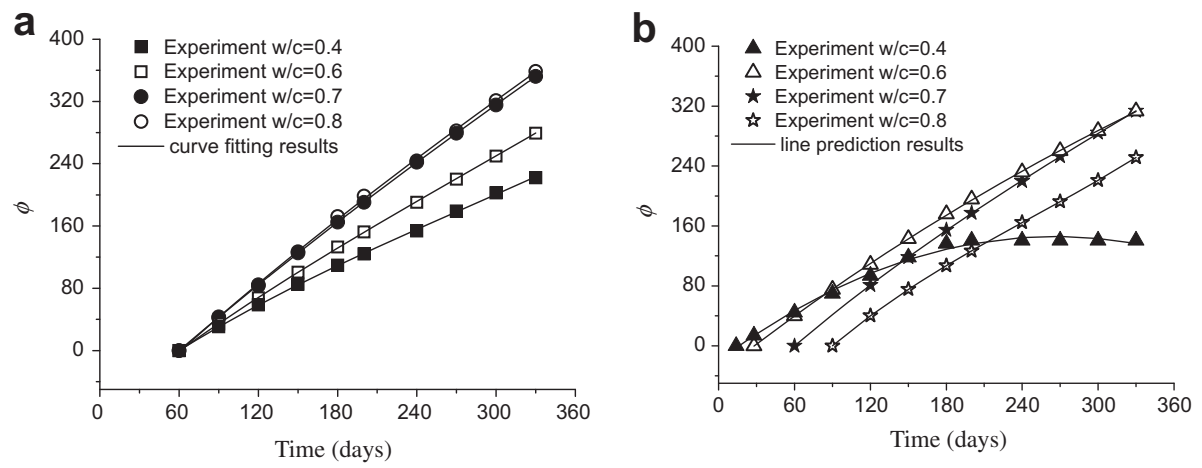

Fig. 8. Variation of $\phi$ with time (a) $\mathrm{Na}_{2} \mathrm{SO}_{4}: 3 \%$ and (b) $\mathrm{Na}_{2} \mathrm{SO}_{4}: 8 \%$.

Form this result we may deduce that there exists a competition mechanism for the variation of the surface hardness of concrete under sulfate attack, namely, enhancement effect of delayed ettringite and weakening effect of damage evolution due to the expansion force of delayed ettringite. In the first stage of sulfate attack, the nucleation and growth of delayed ettringite crystal fills the pores of samples. Such a filling effect may lead to decrease of the porosity of concrete, therefore, the surface hardness of samples increases. In the second stage, the damage evolution induced by the expansion force of the delayed ettringite may lead to the decrease of the surface hardness.

For $w / c=0.4$, hydration is not sufficient in the formation processes. Hence the strength of those samples is lower. In this case, damage evolution may easily take place under the action of delayed ettringite. This was why the surface hardness of such samples monotonously decreases from the beginning of sulfate attack when they are immersed in the sulfate solution of $8 \%$ concentration (Fig. 4a). 
Table 3

Parameters $a_{i}$.

\begin{tabular}{lllll}
\hline \multicolumn{2}{l}{$w / c$} & Parameters & & \\
\hline & $a_{0}$ & $a_{1}$ & $a_{2}$ & $a_{3}$ \\
\hline \multicolumn{2}{l}{$(a)\left(\mathrm{Na}_{2} \mathrm{SO}_{4}: 3 \%\right)$} & & & \\
0.4 & -69.6223 & 1.2422 & -0.00144 & $3.14 \times 10^{-7}$ \\
0.6 & -19.93974 & 1.26449 & -0.00246 & $1.98 \times 10^{-7}$ \\
0.7 & -77.6472 & 1.36273 & -0.00141 & $1.69 \times 10^{-6}$ \\
0.8 & -78.8716 & 1.37254 & -0.00118 & $7.57 \times 10^{-7}$ \\
$(b)\left(\mathrm{Na}_{2} \mathrm{SO}_{4}: 8 \%\right)$ & & & \\
0.4 & -89.32722 & 1.53379 & -0.0007671 & $5.22 \times 10^{-7}$ \\
0.6 & -36.938 & 1.33673 & -0.0009889 & $4.56 \times 10^{-7}$ \\
0.7 & -95.7983 & 1.62922 & -0.00104 & $8.19 \times 10^{-7}$ \\
0.8 & -157.23 & 2.13677 & -0.0049 & $6.60 \times 10^{-6}$ \\
\hline
\end{tabular}

When $w / c=0.7$ or $w / c=0.8$, the porosity of those samples are much larger, which supplies sufficient space for the growth of delayed ettringite. Hence, the increase of surface hardness of those samples at the first stage of sulfate attack is much greater than that of the samples of $w / c=0.4$ or 0.6 (shown in Fig. $4 c$ and $d$ ).

Fig. $4 a, c$, and $d$ indicates that the variation of surface hardness depends on the concentration of sulfate solution. Solution with higher concentration leads to more quickly decrease of surface hardness. However, Fig. 3b presented a different situation. When $w / c=0.6$ (Fig. 4 b) the initial rebound index of those samples is greater than that of the others, which implies that the initial compressive strength of this type of samples is greater than that of other samples. In this case, damage nucleation dose not easily take place, and the enhancement effect is dominant for the variation of the surface hardness. Even in the sulfate solution of $8 \%$ concentration, the surface hardness of the samples remains a constant from $t=28$ days to $t=120$ days, which is much greater than that in other cases shown in Fig. $4 a$, c, and d.

In order to further investigate the growth of chemical reaction products, the experiment of XRD was carried out. The results for the sample (numbed $\mathrm{Z1}$ ) immersed in the sulfate solution of $8 \%$ concentration were plotted in Fig. 7.
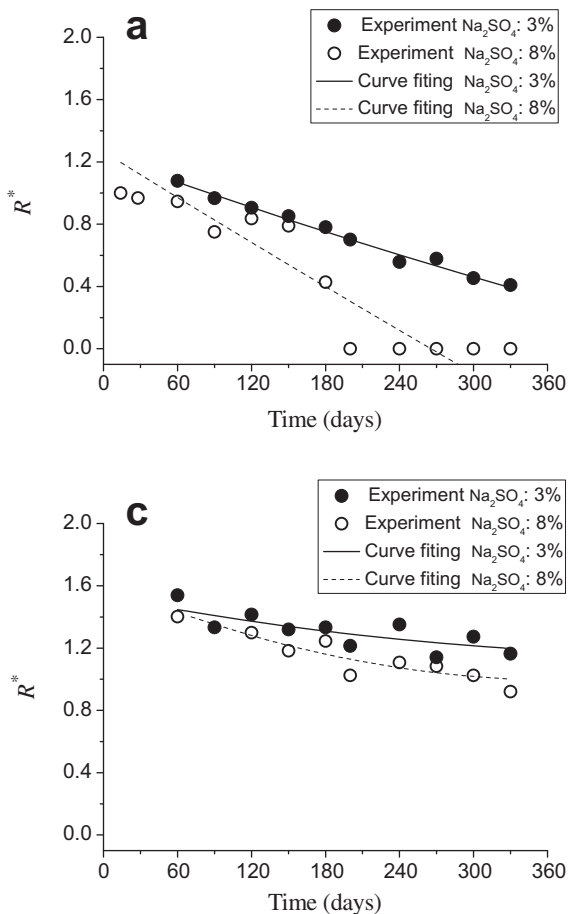

Fig. 7 indicated that not only delayed ettringite, but also gypsum increase with the erosion time. It was well known that gypsum may supply expansion force within concrete materials, therefore, the effect of gypsum on the damage evolution in concrete attacked by sulfate should be also taken into account.

\section{Numerical analysis for attenuation tendency of surface hardness}

Although the decrease of surface hardness is induced by the evolution of erosion damage, it is still hard to directly determine the damage evolution by the variation of surface hardness since its magnitude is oscillating when erosion time $t$ is greater than the critical time $t_{c r}$. Therefore, it is needed to select a stable parameter to describe the degree of the damage evolution.

In fact, the less the damage evolution, the less the surface hardness decreases, and thus the greater the integrating value of the surface hardness with respect to time. Hence, a new method of potential function is suggested to describe the decrease tendency. In this method, a non-dimensional potential function, $\phi$, is defined as follows:

$\phi(t)=\int_{t_{c r}}^{t} \frac{R^{*}(t)}{t_{0}} d t \quad\left(t \geqslant t_{c r}\right)$

where the positive parameter $R^{*}(t)=R(t) / R_{0}$ is a non-dimensional surface hardness, and $t_{0}$ is a reference time (taking $t_{0}=1$ day). It is easy to see that the greater the $\phi$, the less the erosion damage.

According to the experimental results shown in Fig. 3, the numerical results of $\phi$ using Eq. (5) is obtained and plotted in Fig. 8. From Fig. 8 one can see that $\phi$ is a smooth monotone increase function of time. Although the potential function, $\phi$ is still unknown, it can be expanded as a power series of time $t$ as the following:

$\phi(t)=a_{0}+a_{1}\left(t / t_{0}\right)+a_{2}\left(t / t_{0}\right)^{2}+a_{3}\left(t / t_{0}\right)^{3}+\cdots \quad\left(t \geqslant t_{c r}\right)$

Note that
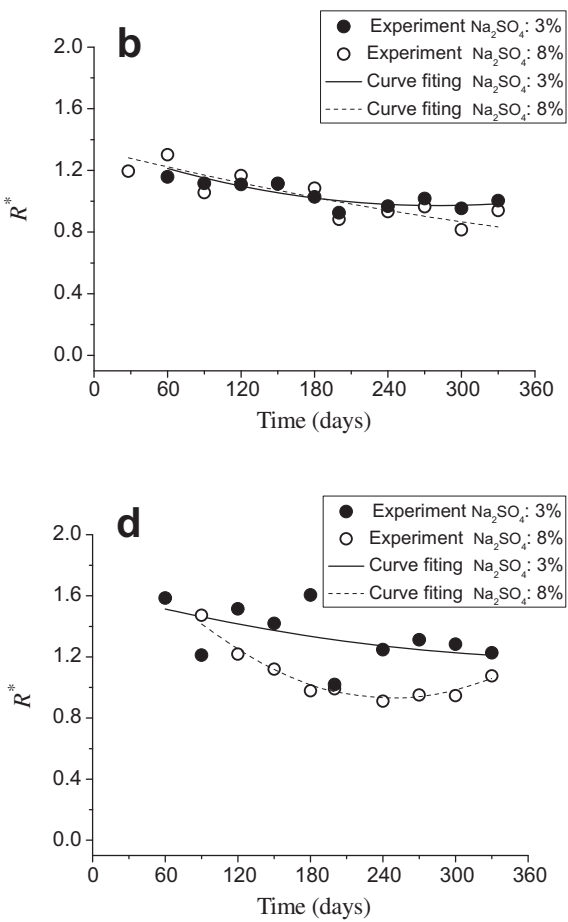

Fig. 9. Variation of $R^{*}(t)$ with time. (a) Sample $\mathrm{H}_{1}(w / c=0.4)$, (b) sample $\mathrm{H}_{2}(w / c=0.6)$, (c) sample $\mathrm{H}_{3}(w / c=0.7)$, and (d) sample $\mathrm{H}_{4}(w / c=0.8)$. 
$\frac{\mathrm{d} \phi}{\mathrm{d} t}=\frac{R^{*}(t)}{t_{0}}=\frac{R(t)}{t_{0} R_{0}}, \quad\left(t \geqslant t_{c r}\right)$

Experimental results shown in Fig. 4 that decrease tendency of $R(t)\left(t>t_{c r}\right)$ is not a linear function, in other word, $\mathrm{d} \phi / \mathrm{d} t$ is not a linear function of time. Therefore, the most simple form of $\phi$ should be a cubic function. Because of this reason, $\phi$ is approximately taken as follows:

$\phi(t) \approx a_{0}+a_{1}\left(t / t_{0}\right)+a_{2}\left(t / t_{0}\right)^{2}+a_{3}\left(t / t_{0}\right)^{3}, \quad\left(t \geqslant t_{c r}\right)$

The coefficients $a_{i}(i=0-3)$ were determined by the best fit of the equation with experimental data, as shown in Fig. 8, and listed in Table 3.

From Fig. 8 one can see that if the solution concentration is $3 \%$ and $t=330$ days, the maximum value of $\phi$ is $\left.\phi\right|_{w / c=0.8}=358.9$, which means that the minimum erosion damage takes place in samples of $w / c=0.8$, since its porosity is much greater than that of other samples, and the expansion force induced by delayed ettringite and gypsum is much less than that in other samples. Otherwise, if the solution concentration is $8 \%$ and $t=330$ days, the maximum value of $\phi$ is $\left.\phi\right|_{w / c=0.6}=313.7$. This means that the minimum erosion damage occurs in samples of $w / c=0.6$, because the initial surface hardness of this type of samples is greater than that of other samples, indicating that the property of corrosion resistance of this type of samples is better than that of other samples.

From Eqs. (5) and (6), the non-dimensional surface hardness of concrete under sulfate attack may be obtained as follows:

$R^{*}(t)=t_{0} \frac{\mathrm{d} \phi}{\mathrm{d} t}=a_{1}+2 a_{2}\left(t / t_{0}\right)+3 a_{3}\left(t / t_{0}\right)^{2} \quad\left(t \geqslant t_{c r}\right)$

Eq. (9) can perfectly predict the attenuation tendency of the surface hardness (shown in Fig. 9), which means that the potential function method may be used to effectively describe the decrease tendency of surface hardness of concrete under sulfate attack.

\section{Conclusions}

This paper has presented a study on the surface hardness of concrete subject to sulfate attack. The following are the conclusions drawn from this study.

5.1. Under sulfate attack, variation of surface hardness of concrete is dominantly caused by the enhancement effect of delayed ettringite and weakening effect of damage evolution due to the expansion force of delayed ettringite and gypsum.

5.2. Generally, sulfate attack may be approximately divided into two stages, in the first stage, the enhancement effect is dominant, and the surface hardness increases; in the second stage, the weakening effect is dominant, and the surface hardness dose not increases, or tends to decreases.

5.3. A new method, i.e., $\phi$-potential function method, was proposed to analyze the attenuation of rebound index. The smooth increasing $\phi$-potential function and its derivative function can be applied to effectively describe the attenuation tendency of surface rebound hardness of concrete materials used in erosion environment.

\section{Acknowledgements}

The authors would like to acknowledge the financial support by the National Natural Science Foundation of China (NSFC \# 10932001, \#51079069), the Key Research Program of Society Development of Ningbo (2013C51007), the Key Research Program of Ministry of Education of China (No. 20103305110001), and K.C. Wong Magna Fund in Ningbo University.

\section{References}

[1] Santhanam M, Cohen MD, Olek J. Mechanism of sulfate attack: a fresh look Part 1: Summary of experimental results. Cem Concr Res 2002;32:915-21.

[2] Santhanam M, Cohen MD, Olek J. Mechanism of sulfate attack: a fresh look Part 2: Proposed mechanisms. Cem Concr Res 2003;33:341-6.

[3] Yimaz AB, Yazici B, Erbil M. The effect of sulfate ion on concrete and reinforced concrete. Cem Concr Res 1997;27:1271-9.

[4] Marchand J, Samson E, Maltais Y, Beaudoin JJ. Theoretical analysis of the effect of weak sodium sulfate solution on the durability of concrete. Cem Concr Compos 2002;24:317-29.

[5] Planel D, Sercombe J, Le Bescop P, Adenot F, Torrenti JM. Long-term performance of cement paste during combined calcium leaching-sulfate attack: kinetics and size effect. Cem Concr Res 2006;36:137-43.

[6] Rozière E, Loukili A, Hachem REl, Grondin F. Durability of concrete exposed to leaching and external sulphate attacks. Cem Concr Res 2009;39:1188-98.

[7] Pipilikaki P, Papageorgiou D, Dimitroula M, Chaniotakis E, Katsioti M Microstructure changes in mortars attacked by sulfates at $50 \mathrm{C}$. Constr Build Mater 2009;23:2259-64.

[8] Plowman C, Cabrera JG. The use of fly ash to improve the sulfate resistance of concrete. Waste Manage (Oxford) 1996;16:145-9.

[9] Chindaprasirt P, Kanchanda P, Sathonsaowaphak A, Cao HT. Sulfate resistance of blended cements containing fly ash and rice husk ash. Constr Build Mater 2007;21:1356-61.

[10] Lee ST, Moon HY, Swamy RN. Sulfate attack and role of silica fume in resisting strength loss. Cem Concr Compos 2005;27:317-29.

[11] Gospodinov P, Kazandjiev R, Mironova M. The effect of sulfate ion diffusion on the structure of cement stone. Cem Concr Compos 1996:18:401-7.

[12] Mironova MK, Gospodinov PN, Kazandjiev RF. The effect of liquid push out of the material capillaries under sulfate ion diffusion in cement composites. Cem Concr Res 2002;32:9-15.

[13] Chen JK, Jiang MQ, Zhu J. Damage evolution in cement mortar due to erosion of sulphate. Corros Sci 2008;50:2478-83.

[14] Chen JK, Jiang MQ. Long-term evolution of delayed ettringite and gypsum in Portland cement mortars under sulfate erosion. Constr Build Mater 2009;23:812-6.

[15] Zhang MH, Chen JK, Zhu J, Chen JY. Experimental evaluation on modulus of equivalent homogeneous ettringite. Acta Mech Solida Sin 2009;22:320-7.

[16] Zhang MH, Jiang MQ, Chen JK. Evolution of flexural strength of cement mortar attacked by sulphate ions. Eng Fract Mech 2008;75:4948-57.

[17] Zhu J, Jiang MQ, Chen JK. Equivalent model of expansion of cement mortar under sulphate erosion. Acta Mech Solida Sin 2008;21:327-32.

[18] Aydin A. ISRM Suggested method for determination of the Schmidt hammer rebound hardness: revised version. Int J Rock Mech Min Sci 2009;46:627-34.

[19] Aydin A, Basu A. The Schmidt hammer in rock material characterization. Eng Geol 2005;81:1-14.

[20] Szilágyi Katalin, Borosnyói Adorján, Zsigovics István. Rebound surface hardness of concrete: introduction of an empirical constitutive model. Constr Build Mater 2011;25:2480-7. 